The Social Sciences 7 (2): 316-320, 2012

ISSN: $1818-5800$

C) Medwell Journals, 2012

\title{
Mastering the Ceramic Practice: Errecting Defences Against Some Areas of Latent Assumptions
}

\author{
${ }^{1}$ Chris Echeta and ${ }^{2}$ Ngozi Ezema \\ ${ }^{1}$ Cross River University of Technology, Calabar, Nigeria \\ ${ }^{2}$ University of Nigeria, Nsukka, Nigeria
}

\begin{abstract}
At every point along the path of pottery production, the practice demands a closely-knitted follow-up both at the material and technical levels. Along this, same path also lie the requirements of personal attention right from the clay deposit to determine its quality in terms of plasticity and clay content. Although, these are professional facts, this study has not spent its energy on them. Rather, the researchers have used this platform to pinpoint and emphasize those areas that confront studio practice at the levels of performance and assumptions. These assumptions which are potentially harmful to practice carry their offences to the doorsteps of glazes their materials, handling and firing. This study considers these offences and generates defences which ceramic professionals must erect to ensure safe and successful studio practice.
\end{abstract}

$\underline{\text { Key words: Ceramic practice, glazes, proper labelling, material identification, foot-cleaning, Nigeria }}$

\section{INTRODUCTION}

The aspiration of every effort in any field of endeavour is to arrive safely at an expected destination. Therefore, it is with ceramists who spend time and energy pursuing their goals. For such, the peculiarity of their medium and the complex technical requirements stretch their commitment to limits and widen the length and breadth, even as they deepen the extent of production scope. Within this production ambience, no guesswork or assumptions ought to be tolerated. The reality of this posture is that ceramic vessels hold no meaningful value, either as utility objects or as decorative pieces if they are not subjected to firing.

The captivity of heat and its retention is guaranteed in a thermal cubicle known as a kiln or kin. This thermal facility does not only fire bare clay objects but also clay works on whose bodies some compounded materials known as glazes are applied. The ability to compound the materials calls for proper identification of all the items which go into the compounding. In fact, a successful glaze-making relies on the proper and correct identification of the glaze materials.

\section{MATERIALS AND METHODS}

Raw material identification through proper labelling: Ceramic materials are usually packaged as powdered substances which may have passed through between 120 and 150 mesh sieve. Some can also be up to between 200 and 250. Mostly white or whitish, they chromatically resemble each other in many cases. In terms of packaging weight, the materials may or may not be the same. In other words, sizes and package weights cannot be used to identify glaze raw materials. Even colouring oxides share in this similarity question. Granted, some colouring oxides can be identified with their colours but others leave the ceramist helpless once the labels are not in place. Black iron oxide, nickel and manganese dioxide look alike so much that proper labelling is the only way forward for the ceramic producer.

Harmful ceramic materials constitute a part of the ceramic production raw materials. Barium carbonate and other compounds of lead are readily implicated in this group. For a ceramic producer to take the necessary precautions against such, proper identity must be unmistakable. Speight and Toki (2004) in Hands in Clay (5th edition) noted the importance of safety in ceramic production. They said:

To be sure that you know what you are using carefully read labels and any warnings and ask your supplier to give you the appropriate Material Safety Data Sheet (MSDS) that reveals any hazardous ingredients, the effect of exposure and the necessary protection and precaution information

Against the above background, identification through proper and/or timely labelling provide easy access to the person and the character of the material.

Corresponding Author: Chris Echeta, Cross River University of Technology, Calabar, Nigeria 
This proper identification includes not just the name but also their visual and tactile nature as well as their toxicity or otherwise. Sometimes, the labels should contain other pieces of information like their chemical composition or even the grain size expressed as coarse or fine. These additional information back-ups help to alert practitioners as to how to put the materials to use. Labels usually follow the materials from the manufacturers to the shops or to studios as the case may be. These researchers wish to emphasize that once the labels are lost or even mixed up; the products/materials ought not to be used any more. At that level, it becomes very difficult or impossible to locate and assign the right materials to the right recipes. They are lost and little can be done about it. Many of the materials used in ceramic manufacture are not chromatically distinguishable as has been hinted above. Mislabelling has exploited this fact. The thin line of visual similarity between milled feldspar and flint for example, makes it easy to mistakenly swap them for use. Barium carbonate, a harmful ceramic glaze material is potentially implicated in the possibility of mistaken use as it looks like many other substances at the disposal of a ceramic manufacturer. The same goes for label less or mis-labelled toxic lead compounds.

Proper and improper labelling: Various labelling techniques have been used in material identification, both for liquids, solids and powder. From $>2$ decades of ceramic practice, two methods have consistently served well. The 1st recommended type is that in which the name of the material, nature and characteristics are printed directly on the packaging container. This method can be said to be full-proof provided the printing ink used neither bleeds nor washes. This type of labelling, ordinarily, cannot be detached or cut off accidentally without leaving a loud suspicion. The 2 nd type is done by sticking the particulars on the bags or containers housing the materials. This works quite effectively but the chances of label loss still exist. This may be caused by ineffective sticking or the absence of enough gum grip. The third class of labelling technique which these researchers do not recommend at all is what they have called the Airport Labelling Technique. This is the type which follows the format of luggage identification system at airports. Such labels are tied to the materials using a rope or a string. The major disadvantage of this method is a high possibility of snapping or cutting leaving the package nameless. Woody (1979) defines a glaze as a glass coating melted in place on a ceramic body. This glaze is made of materials which should be well-packaged and kept track of. Proper identification for correct material access is then not selective in ceramic production.
Effective labelling which is a gateway to identity ought to be comprehensive. No practitioner will consciously ignore a resource.

Identifying convenient packs: More often than not bulky bags or containers of raw materials are not easily moved from one place to the next. They prove too unwieldy for such frequency of movement. To get around this problem, convenient quantities are scooped out from those large bags and put to use. Sometimes, these convenient quantities may be as large as between 5 and $10 \mathrm{~kg}$. Many a time such scoops are not exhausted once and may have to remain on the shelf to await the next time of demand. To prevent avoidable losses, these convenient packs ought to be labelled immediately they are scooped. The question of; I will remember and do it later does not arise. The identities of such materials can quickly be written on gum strips or scotch tapes and stuck in place immediately. This practice will save the ceramist from the grief of repeated material losses or from something more dreadful. On the other hand, such identities can be written on pieces of papers and dropped into their containers for quick referencing. However, the disadvantage of this practice is that the material in which the piece of paper is thrown will within a short while start eroding the information making it illegible. In addition to that these pieces of paper may by accident be mixed up for whatever reason. Matching them will then be impossible or at best be guesswork which is unacceptable for ceramic practice.

Glaze storage system: Compounded glazes are usually stored in buckets or in other containers and brought into the workshop for use. As opposed to metal containers, plastics are the more appropriate vessels for glaze storage. This is because metals corrode with time, especially when exposed to moisturized environments. Glazes stored in containers sometimes share strong visual presentations. The look-alike nature may be so intense that the prospects of mistaken identity will be quite sonorous yielding to mistaken identification. Base glazes, white or opacified fall into the above category quite easily. Coloured glazes generally present less problems of identity because of their peculiar colours. Having said this, it must be remembered that some ceramic colours also look like others in their raw or unfired state. Implicated in this scenario are black iron oxide, nickel oxide and manganese dioxide, even copper oxide, to mention but a few.

Sometimes, studio owners/practitioners store glazes in containers which bear the same colour as the glaze in them the same. The propriety of this they tend to justify by the argument that when for instance, green glaze is 
stored in a green container, chances of mistaken identification does not exist. This erroneous argument fails to observe that there are very many shades of green in a ceramic colour palette. So are other colours. Again, there are middle shades like greenish yellow, reddish brown, bluish black and so on. To further weaken the argument in favour of Container Colour Storage Technique, glazes have their nature or characteristics. Some are smooth while others are rough, some glossy even as others are matte. Others come in streaks while yet others are quiet in their outlook. It is very impossible to follow all these with Container Colour Technique of identification. It may be necessary to point out that colours on plastics fade faster than people may be willing to accept. In the light of this, the colour of the glaze inside and the colour of the same container outside part ways leading to mistaken identity.

Comprehensive labeling may threaten studio secrets, as some practitioners think. This may, to some extent, be true. These researchers wish to remind such professionals that by using comprehensive labeling, they have not given away their batch compositions. To further douse such fears, letter or figure coding or a combination of such may be used on the material and bucket containers. For instance, $\mathrm{A}$ or $\mathrm{B}$ or 2 or even 3 or any other letter or figure for that matter can be ascribed on such containers. Combinations may look like this, A1, A2 or 1A, C3 and so on. The interpretations of such letter codes or their combinations can then be translated in private safes or personal diaries away from public reach. The codes may include material type, batch formula, colour or firing temperatures. The interpretative access will be for the exclusive consumption of the studio owner or any other accredited person. In this way, the hallowed secrecy and the information integrity of the set-up can still be watertight.

\section{RESULTS AND DISCUSSION}

Foot-cleaning mistakes and assumptions: Foot-cleaning resides in the 2 nd half of production compartment. It is like a bridge between the biscuit and the glaze firing stages. It is a hand-over ground upon which the success or otherwise of glaze firing is determined, other things being equal. Before this point, the studio master ought to have mastered most of the technical demands of production, both in the utility sector and in the aesthetics. Rhodes (1959) puts it this way, the potter must train himself in his craft until technique can become assimilated into himself. His technical control and his creative insights must be part of the same thing. For many ceramic artists and practitioners, dusted and cleaned wares are clustered on a wide table or raised platforms ready for glazing. These wares are glazed, either by dipping or pouring with their feet also covered with raw glaze. These two methods are the most commonly used techniques by studio owners in Nigeria. As the seats of the ceramic wares are usually covered with glazes, it becomes imperative that foot-cleaning should be thorough to prevent stuck ware. Long years of studio production have shown that at this stage, many assumptions constitute serious mistakes which cause success leakages in terms of casualty percentage.

Cleaning in situ: The term, cleaning in situ has been used here to refer to a foot-cleaning attitude whereby wares are lifted from the table, foot-cleaned and put back into the same space from where they are lifted. There are three major and far-reaching disadvantages of this style. First, because the wares have been clustered or lined up on the congested table or platform, there is no visual access to which foot has been cleaned. Cleaned and uncleaned ceramic pieces are therefore mixed up together.

The implication of the above mix-up is that many uncleaned are mistakenly counted among the cleaned. This happens ordinarily but more so when the fettler is getting fatigued due to long hours of work. The 2nd disadvantage is that when wares are being returned to the clustered table after cleaning, chances are usually high that ware-to-ware contact will be repeatedly made therefore, causing smudges and bare surfaces on the pieces. These when fired, leave unsightly and starved areas. The 3rd draw-back of this method is that when wares are raw-glazed and placed on a particular table space. It is from these spaces that they are lifted and fettled and then placed back on the same space. Their seats or feet get smeared again by the glaze deposited on the table when the pieces were dipped and placed on the table. Many a time, these glaze smears look innocent and harmless but their destructive capacity ought not to be ignored. For such smeared ceramic pieces, stuck ware remains the inevitable production leakage.

New Site Method in foot-cleaning: Unlike the in situ Foot-Cleaning Approach, the New Site Method is just the opposite. It is a situation whereby feet are cleaned and deposited at new sites. This involves a clear and definite spatial demarcation between the cleaned and the yet uncleaned. The two sites, one for the uncleaned and the cleaned can be accommodated on the same table. Both can also be placed on the studio floor. Or still, one on the table and the other on the studio floor or elsewhere. By this differential siting, the chances of mistaken assumptions about cleaning do not arise neither do they 
exist. The necessity for adequacy of space cannot be over-emphasized. One must first of all, make sure one's production space is adequate.

When the wares are lifted for cleaning as was mentioned before they leave glaze smear on heir trail. After cleaning the seat, the wares under this method are placed at new sites thereby becoming properly accredited for loading into the kiln for firing. The new sites can be designated left or right or up or down if one is lower than the other. The boundaries of mistakes with this differential siting are pushed back for the benefit of proper production. One may argue that it is acceptable to lift, clean the foot, clean the spot from where that ware was lifted and place back the piece. Much as this idea looks mistake-free, the facts on the ground during consistent production say otherwise. It also does not answer the question of rubbing off and smudges due to close packing.

Kiln-loading for glaze firing: Kiln-loading for glaze firing does not constitute in the packing of cleaned wares into the kiln. On the contrary, it can be described as the systematic and thoughtful placement of wares in the kiln interior based on certain technical reasons and objectives. When glazes are applied on wares and fired to their maturing temperatures or thereabout, they stick to or catch any objects they have made contact with inside the kiln as they cool down, including each other. A lot of care is therefore needed when packing a kiln for glaze firing. Care must be taken when packing a kiln for a glaze firing. Unlike in the biscuit firing, pots should not come in contact with one another or they will stick together once the glaze melts (Cosentino, 2002). Unless for the purpose of design, such wares are meticulously placed in such a way that contact is completely avoided. In such a project, carelessness and lack of knowledge frequently conspire to ruin the primary objective of firing. A good ware placement must entertain inter-ware spaces which will respect the thermal character of the glaze in use and yet not become space wasting. Many studio owners of practitioners know this theoretically but in practice, they may strike it right by chance sometimes. It ought not to be so. Learning more makes them to get it right always.

Loading the kiln starts from the inside for front-loading kilns that is from the back wall towards the loader at the front door. In a multi-stack loading where there are vertical columns, the farthest stack or column should be the first to be erected. Once the 1st line of loading is established on the batt, the loader's view between this 1 st and 2 nd line becomes obscure. $\mathrm{He}$ is no longer able to determine how near or otherwise the front row is from the one behind it. Getting over this, obscurity problem is diligence-based. The loader places a ware on the batt inside the kiln and gradually but steadily moves it towards the preceding line of wares until contact is made. He then pulls it backwards a little bit towards self, thereby creating a space between that piece and the one behind it. Once this method of pull-back is consistently adopted, the mandatory inter-ware space will always be achieved which guarantees no-stuck ware position. Having said this, the spatial magnitude of the pull-back will be dependent on the thermal characteristics of the glaze on the wares. Glazes that boil at their melting point require more space than those that do not boil. If more space is not given for boiling glazes, contact will be established during the boiling stage which will not break during cooling. Well-formulated glaze batches have enough to establish a coat over a ceramic ware. Such hardened coats resist the development of smudges on the glaze surface during handling or inter-ware contact. Clay, gum arabic and lumps of common sugar can be introduced into batches to toughen glaze coating. These, however, do not provide a license for excessive handling after a glaze has been applied on wares. Every inevitable handling must be done carefully to prevent the wounding of the glaze coat or surface.

Kiln-loading ought to be based on space-thrift. In fact useful but wasted spaces are a thing of great pain for serious ceramic studio artists. There, however, comes a time when a critical choice has to be made between generous space loss and the loss of the entire firing:

For effective viewing, the spy hole size should be in the neighbourhood of $3 \times 4$. It can, however, be a little more but not big enough to admit cold air into the kiln suddenly for obvious reasons, thermal shock and consequent possibility of cracking (Echeta, 2004)

The researcher goes ahead to say that this extravagant space allocation which must be within professional reasoning. While agreeing with the allocation of a generous space, Chris Echeta counsels that the strict pursuit of the economy of space does not arise. This is as far as it is professionally expedient.

\section{CONCLUSION}

The research has been targeted to the fine-tuning of some blur and discordant areas of ceramic production and to establish definite and correct production boundaries beyond those drawn by wrong assumptions. Larger areas of troubled practice exist but these researchers believe that those handled here will minister healing to the numerous but quiet sufferers dying in silence. It is also hoped that there will be a resurrection of professional zeal fired on by diligent and correct learning which this study has set out to project. After now, the researchers believe many practicing potters will be challenged to put their 
experiences acquired over the years in black and white for the benefit of the profession and humanity.

\section{REFERENCES}

Cosentino, P., 2002. The Encyclopedia of Pottery Techniques: A Comprehensive Visual Guide to Traditional and Contemporary Techniques. Sterling Publishing Co., Inc., New York, ISBN: 9780806989136, pages: 192.
Echeta, C., 2004. Glost firing: Beyond thermosensors. CPAN. J. Ceramics, 1: 14-19.

Rhodes, D., 1959. Stoneware and Porcelain: The Art of High-fired Pottery. Chilton Book Company, Pennsylvania.

Speight, F.C. and J. Toki, 2004. Hands in Clay. McGraw Hill, New York.

Woody, E., 1979. Handbuilding Ceramic Forms. John Murray, London. 